\title{
Um medalhão para a fortuna e uma virtù para pandora: Machado de Assis e Maquiavel'
}

\section{A medallion for fortune and a virtù for pandora: Machado de Assis and Machiavelli}

\author{
Daniel Benevides Soares
}

https://orcid.org/0000-0001-7275-9217 - E-mail: benevides.soares@gmail.com

\section{RESUMO}

Propõe-se um paralelo entre Machado de Assis e Maquiavel. Para tanto, dividiu-se o artigo em quatro seções. Na primeira, apresentam-se duas relações possíveis entre Machado de Assis e a filosofia: uma leitura da não relação e uma leitura da relação. Na segunda, discute-se a interpretação de Margutti sobre a relação entre Machado e a filosofia. Na terceira, toma-se a leitura de Maia Neto da ficção machadiana. Na quarta seção, constrói-se o paralelo entre Machado e Maquiavel tendo como base os conceitos apresentados nas etapas anteriores. Finaliza-se com um balanço do paralelo.

Palavras-chave: Machado de Assis. Maquiavel. Literato-filósofo. Ficção cética. Virtù. Fortuna.

\section{ABSTRACT}

This paper proposes a parallel between Machado de Assis and Machiavelli. Therefore, the paper was divided into four sections. In the first, two possible relationships between Machado de Assis and philosophy are presented: a reading of non-relationship and a reading of relationship.

\footnotetext{
1 Agradeço imensamente aos professores Paulo Margutti, José Raimundo Maia Neto e Evanildo Costeski pela gentil leitura da versão inicial desse trabalho e pelos comentários argutos. A versão final desse texto recebeu o benefício da sabedoria dos três.
} 
The second part discusses Margutti's interpretation of the relationship between Machado and philosophy. In the third stage, Maia Neto's reading of Machado's fiction is presented. In the fourth section, the parallel between Machado and Machiavelli is built based on the concepts presented in the previous steps. It ends with a discussion of the parallel.

Keywords: Machado de Assis. Machiavelli. Philosopher-literate. Skeptical fiction. Virtù. Fortune.

\section{Introdução}

Nosso objetivo é realizar um uma investigação a respeito da ação humana por meio de um paralelo entre Machado de Assis e Maquiavel. Centraremos nossa análise no conto Teoria do medalhão e no capítulo VII O Delírio das Memórias Póstumas de Brás Cubas. A partir desses dois textos, propomos o paralelo com os conceitos maquiavelianos de virtù e fortuna. Para levar a cabo essa intenção, propomos uma pesquisa dividida em quatro etapas. A primeira destaca dois modos de situar Machado de Assis em relação à filosofia, segundo os seus respectivos partidários considerem que haja uma proximidade maior ou menor. Seguindo uma das posições apresentadas no momento anterior, nas etapas seguintes discutimos duas interpretações sobre a articulação entre filosofia e a obra machadiana, a de Paulo Margutti e a de José Raimundo Maia Neto. Colhendo os resultados dessas análises, concluímos com o cotejamento entre os autores de $O$ príncipe e de Teoria do medalhão. Esperamos assim contribuir de alguma maneira com um debate sobre os dois autores pela perspectiva recíproca.

\section{O Bruxo e a Coruja}

A discussão que situa Machado de Assis $^{2}$ em relação à filosofia é antiga, extensa e intrincada, como atestam os trabalhos de Alex Lara Martins ${ }^{3}$, Maria Rosa Dias ${ }^{4}$ e Marcos Ferreira de Paula ${ }^{5}$. Entretanto, ainda assim é possível tentar resumi-la em duas posições antagônicas: de um lado, defende-se uma relação mais estreita entre o Bruxo do Cosme Velho e a filosofia, de outro, considera-se que esse vínculo é meramente incidental. No segundo partido, podemos alocar as leituras de Miguel Reale e Benedito Nunes. Como exemplos da primeira posição, temos como referência Paulo Margutti e José Raimundo Maia Neto. Passemos brevemente em revista essas quatro leituras, começando por aquelas que consideram que entre Machado de Assis e a filosofia inexiste uma relação profunda, o que denominamos de uma leitura da não-relação.

Miguel Reale considera que as menções a pensadores como Pascal e Schopenhauer na obra machadiana são ilustrações para as discussões, não constituem uma dimensão propriamente filosófica, mas são caracterizadas como um material teorético, uma espécie de metateoria. Essa metateoria configura uma teoricidade, que, na acepção de Reale, confere à teoria o significado de uma hipótese e não uma consideração reflexiva mais profunda. Teoria, portanto,

\footnotetext{
${ }^{2}$ As referências aos textos machadianos serão dadas pela abreviação das Obras Completas seguida do número do volume e da página. A exceção será os textos da obra Contos esparsos.

${ }_{3}$ Conferir a esse respeito (MARTINS, 2009, p. 13-24). Conferir também (MARTINS, 2017).

${ }^{4}$ Conferir a esse respeito (DIAS, 2005, p. 382-392). Para uma interpretação crítica da relação entre Schopenhauer e Machado de Assis, ver (MARGUTTI, 2007, p. 205).

${ }^{5}$ Conferir a esse respeito (PAULA, 2018, p. 1-18).
} 
significa nesse sentido uma hipótese provisória, uma investigação, de valor mais amplo e simbólico, que funciona como uma espécie de complemento para os modelos de sua ficção artística. Segundo essa interpretação, na obra de Machado é possível falar mais dessa teoricidade do que propriamente de uma tratativa dos problemas em termos estritamente filosóficos $(1973$, p. 6).

Compartilhando de leitura análoga, em Benedito Nunes Machado aparece como um autor cujos elementos filosóficos estão indissoluvelmente ligados à sua ficção ${ }^{6}(1989$, p. 10). Nunes inicia sua análise da relação entre Machado e a filosofia elencando os autores cuja influência se fez notar pelos críticos na obra machadiana: Pascal, Schopenhauer, Pirro, Montaigne $(1989$, p. 10). Para o intérprete, no entanto, o verdadeiro sujeito hermenêutico nessas relações seria a obra ficcional machadiana, que absorve as filosofias conferindo-lhes uma intenção diversa daquela que possuíam originalmente enquanto discurso filosófico, constituindo assim mais um pensamento ficcional do que propriamente uma filosofia. Para Benedito Nunes, se há uma relação estabelecida entre o Bruxo do Cosme Velho e a filosofia é uma relação lúdica, em que Machado zomba da rainha das ciências (1989, p. 9-11). Essa relação permeada pelo humor constitui o que o autor denomina o pensamento ficcional do narrador (NUNES, 1989, p. 12-14). Nesse pensamento ficcional do narrador, conjugam-se com o humor um pessimismo e um ceticismo, sem, contudo, constituírem um plano sistemático, no sentido da exposição de uma filosofia (NUNES, 1989, p. 15-16).

As leituras da não-relação entre Machado e a filosofia podem ser contrapostas por aquelas que consideram uma maior aproximação entre a obra do Bruxo do Cosme Velho e a coruja de Minerva, de modo que as fronteiras entre a filosofia e a literatura não são tão bem definidas. Essa perspectiva considera a filosofia sob uma perspectiva mais ampla em relação ao que tradicionalmente se concebe como sistema. Destacaremos duas dessas leituras - uma que leva em conta a contribuição da literatura para a especificidade da filosofia brasileira pelo conceito do literato-filósofo e a outra que salienta a importância da forma ficcional para a exposição de uma determinada filosofia cética. Ambas denominamos leituras da relação. Começamos, então, com a de Margutti, em seguida, passando para a de Maia Neto. Os conceitos das duas leituras em combinação construirão as bases para a etapa final da pesquisa.

\section{Além de cético, pessimista}

No primeiro volume da sua História da filosofia do Brasil: O período colonial (1500 - 1822), Margutti apresenta o literato-filósofo, em conjunto com o diplomata-filósofo, como um traço constitutivo do cenário filosófico nacional, rastreado a partir da Matriz Filosófica Colonial. Machado assim aparece em conjunto com outros literatos, tais como Guimarães Rosa, Graciliano Ramos e Clarice Lispector, que expressam intuições filosóficas relacionadas com suas respectivas épocas históricas (MARGUTTI, 2013, p. 40). Para compreendermos o papel desempenhado pelo literato-filósofo é imprescindível passarmos pela apresentação da Matriz Filosófica Colonial marguttiana. A Matriz Colonial expressa a visão de mundo ibérica nos seus aspectos preponderantes: ceticismo, estoicismo e salvacionismo (MARGUTTI, 2010, p. 107-108). Para o nosso propósito, contudo, interessam principalmente os elementos ligados à forma literária.

Essa matriz recebe sua forma do processo de modernização, a modernização conservadora, atravessada pelos povos ibéricos, que constitui um processo de modernidade alternativo

\footnotetext{
${ }^{6}$ É interessante notar que o traço tido por Nunes como o que desvincula Machado da filosofia é o que o relaciona, segundo Maia Neto. Conferir a esse respeito (MAIA NETO, 2007B, p. 212-213), bem como (MAIA NETO, 2016, p. 277-279).
} 
ao da Europa setentrional, caracterizado pela sua postura pragmática. Uma maior valorização da ação e certa desconfiança da teoria também marcam essa postura do ponto de vista filosófico. Como consequência, surge da parte dos autores ibéricos primeiramente uma adoção de uma postura exegética, como forma de aderir a sistemas já formulados, pelo receio em formular sistemas próprios; surge também aqui um ceticismo, como consequência da constatação de que nada se pode conhecer (MARGUTTI, 2010, p. 104-106).

O problema do ceticismo em sentido estrito pode ser solucionado através da produção de obras de caráter mais literário do que filosófico, em que o autor expressa sua reação emocional diante da realidade, ao invés de explicá-la teoricamente. A visão cética é geralmente produzida a partir de alguma forma de pessimismo religioso na avaliação do mundo, que é visto como fonte de todos os males e tentações (MARGUTTI, 2010, p. 106).

Sócrates aparece como um paradigma para os filósofos lusitanos, por encarnar grande parte das características que podem ser encontradas também no pensamento ibérico (MARGUTTI, 2010, p. 106-107). Influenciado pela douta ignorância socrática (MARGUTTI, 2010, p. 126), Francisco Sanches ilustra em seu pensamento os traços fundamentais da visão filosófica ibérica (MARGUTTI, 2010, p. 135-136), incluindo a inquietação intelectual, a postura intuitiva, antissistemática e religiosa dos lusitanos (MARGUTTI, 2010, p. 110). A importância de Sanches se dá como representante de um paradigma - não se trata de uma escola - filosófico cuja influência se fez sentir mesmo nos autores brasileiros, ainda que indiretamente 7 . Trata-se de uma postura, oposta à exegese de tipo escolástico, que se caracteriza por sua a-sistematicidade e criticidade, como vetor da inquietação humana frente ao elemento ineludivelmente enigmático do existir. No Período Colonial, essa postura ganhou mais força no Brasil do que em Portugal, cedendo lugar para uma posição mais sistemática na época do Império (MARGUTTI, 2010, p. 136-138).

\section{Mesmo assim, ela também sobrevive entre nós, de maneira um tanto subterrânea, conforme mencionado, manifestando-se esporadicamente através dos textos de literatos com dotes filosóficos, como Machado de Assis, Clarice Lispector e Carlos Drummond de Andrade (MARGUTTI, 2010, p. 138).}

Segundo Margutti, essa visão de mundo conforme expressa na Matriz do catolicismo barroco vicejou por cerca de três séculos até que o século XIX assistisse uma mudança progressiva que ensejasse finalmente a crescente produção filosófica acadêmica vivenciada no Brasil a partir do século XX. Essa espécie de "ceticismo literário" enquanto um dos componentes da Matriz Colonial, entretanto, não desapareceu inteiramente, de modo que ainda exerce influência o suficiente para abrir veios por onde possa escoar. É o caso também na sua época de Machado de Assis, que apresenta ligações, ainda que implícitas, com essa fonte originária (MARGUTTI, 2007, p. 185).

De acordo com Margutti, a Matriz Colonial expressa um pessimismo de natureza moral baseado nos princípios cristãos e que desconfia dos poderes da razão humana. Isso conduz a uma rejeição das teorias sistemáticas (2007, p. 184-185).

Esse pessimismo moral que desemboca no ceticismo e que, para abreviar, denominarei pessimismo cético, é compatível com uma postura estóica do mundo e com o salvacionismo da religião católica. No Brasil Colônia, essa matriz se apresenta partilhada por diversos

\footnotetext{
7 "Nessa perspectiva, um autor cuja visão de mundo tenha afinidades com a tendência de expressar a inquietação existencial num viés assistemático e cético poderia ser chamado de sanchista, mesmo que nunca tenha lido as obras de Francisco Sanches" (MARGUTTI, 2010, p. 137). Acreditamos que Machado se enquadra perfeitamente nessa descrição.
} 
autores, como Nuno Marques Pereira, Gregório de Matos, Antônio Vieira e Matias Aires (MARGUTTI, 2007, p. 185).

A inspiração na visão de mundo do Eclesiastes se faz notar, espelhando o caráter repisado da miséria humana, além da vaidade inerente à pretensão de conhecer. Em um espírito pascaliano, o modo de compreensão intuitivo e cordial, relacionado ao coração, prepondera sobre a razão. (MARGUTTI, 2007, p. 185). Esse espírito pascaliano, assim como a influência de Montaigne, deve ser entendido na verdade como uma confluência da visão de mundo cujas raízes remontam ao pensamento de Francisco Sanches. É nesse horizonte que se compreende a exposição de Machado do Humanitismo enquanto uma crítica aos sistemas filosóficos empenhados em fornecer uma projeção otimista da existência humana no mundo (MARGUTTI, 2007, p. 203-204).

Daí o trocadilho machadiano de sentido profundamente filosófico, quando ele afirma, em Memórias Póstumas, que o autor'escreve usando a pena ${ }^{8 \prime}$. A pena, aqui, não é apenas a caneta com que se escreve, mas também, e principalmente, o sofrimento humano (MARGUTTI, 2007, p. 204).

A maneira de lidar com essa constatação da miséria humana oferecida por Machado é uma forma de criação literária, que viabiliza uma contemplação estética da miséria humana, de modo que o texto adequado à expressão da realidade deve espelhar o caráter multifacetado, enigmático e dúplice da própria existência, gerando uma diversidade interpretativa, uma polissemia, afim ao caráter impenetrável do próprio real (MARGUTTI, 2007, p. 204).

Isso é bastante perceptível na segunda fase da sua ficção. Aqui, os narradores são sempre contingentes, historicamente localizados e, acima de tudo, pouco confiáveis. Mesmo assim - e esse talvez seja o ponto crucial para entender Machado - Cada um desses níveis de leitura é consistente com a visão pessimista-cética da vida humana. É como se Machado quisesse mostrar que nossa condição miserável é a mesma e possui uma bela forma sob qualquer leitura possível (MARGUTTI, 2007, p. 204).

Tanto esse pessimismo cético como a saída estética encontram um ponto de articulação na ironia machadiana. Essa ironia surge como postura ético-filosófica que revela as falhas na conduta humana. A ironia é um dos pontos que é apresentado no conto Teoria do medalhão (MARGUTTI, 2007, p. 205).

O ironismo machadiano parte do pressuposto de que não há nada de novo debaixo do sol e se articula com a criação literária, num espírito recomendado por Rorty, quando ele afirma que os textos literários são mais adequados do que os filosóficos para expressar nossas visões de mundo (MARGUTTI, 2007, p. 205).

No referido conto, o desfecho menciona O príncipe de Maquiavel. Comparar alguns aspectos dos autores pode servir, portanto, para uma compreensão mais profunda de certos conceitos e aspectos de ambos, como o significado da ação humana e o modo como os elementos

\footnotetext{
8 "Obra de finado. Escrevi-a com a pena da galhofa e a tinta da melancolia, e não é difícil antever o que poderá sair desse conúbio" (OC, l, p. 599). Esse consórcio talvez seja uma chave para a compreensão da ironia machadiana. Como Machado escreve no Prólogo da Quarta Edição, o "sentimento amargo e áspero" que constitui a alma do livro, por mais risonha que aparente, marca uma distância em relação aos seus modelos: Xavier de Maistre e Sterne; a taça que leva o amargo e áspero vinho machadiano vem da mesma lavra que a dos autores mencionados, porém, o conteúdo diverge; aqui o Bruxo do Cosme Velho alude com o recipiente à forma livre, mas o conteúdo, pondera, é outro (OC, I, p. 599): seria a ironia uma receita composta de um terço da taça de zombaria (o'áspero' no sentimento e a 'galhofa' da pena) e dois terços de pessimismo (dois terços porque além do 'amargo' no sentimento e da 'melancolia' na tinta, há o trocadilho da pena; o resultado final dessa alquimia compõe as chamadas 'rabugens de pessimismo' metidas na forma)?
} 
subjetivos estão relacionados com esse agir. Esse cotejamento é o método do paralelo aplicado às questões da filosofia brasileira?.

Margutti também apresenta sua visão da relação entre o Bruxo do Cosme Velho e a filosofia no debate sobre a leitura de Maia Neto ${ }^{10}$, segundo a qual na obra machadiana percebe-se a busca e a lapidação progressiva de um tipo de personagem-narrador ideal, encetada ainda nos primeiros contos e levada a cabo com o Conselheiro Aires (MAIA NETO, 2007B, p. 223). Essa ficção cética, conforme Maia Neto, é indissociável da forma literária, não se tratando, portanto, de uma postura pessoal assumida por Machado, de modo que é equívoco idêntico tanto analisar a filosofia cética separando-a da forma literária ${ }^{11}$, quanto analisar a forma literária sem levar em conta a presença de uma filosofia cética (MAIA NETO, 2016, p. 278-279).

O ceticismo apresentado por Maia Neto é aproximado ao pirronismo, porém mantendo elementos do ceticismo pirrônico moderno visto em autores como Hume, Pascal, Erasmo e Montaigne (MAIA NETO, 2007B, p. 212). Nessa perspectiva, os elementos componentes do pirronismo - zétesis, epoche e ataraxia - se desenvolvem ao longo da obra machadiana, incluindo a primeira fase, atingindo a forma mais bem acabada com os narradores memorialistas da segunda fase (BERNARDO, 2007, p. 172-173). Importa ponderar que esses três elementos não surgem rematados, mas são aprimorados progressivamente ao longo das duas fases (MAIA NETO, 2007A, p. 17). Maia Neto elabora algumas categorias fundamentais, cuja articulação desenvolve a filosofia contida na ficção cética machadiana. Inicialmente destacamos entre essas categorias básicas a paz de espírito e a vida exterior. Enquanto a primeira representa um lugar de transparência no significado das ações, sem hiato entre um gesto e seu significado, lugar, portanto, onde é possível falar de uma verdade e de uma eticidade que se coadunam com a transparência, a segunda representará seu exato oposto: lugar de dualidade, de aparências. $\mathrm{O}$ casamento é a ilustração mais característica da paz doméstica na primeira fase, deixando, na segunda fase, essa condição para compor também a vida exterior (MAIA NETO, 2007A, p. 24).

Ora, será essa invasão do casamento pela vida exterior que resultará na crise cética, cuja resposta culmina na postura do narrador cético, o memorialista que busca uma saída estética para viver o seu ceticismo. Quem vive essa crise cética é um dos tipos de personagem que não se adapta à vida exterior, em oposição ao que se adapta. Temos então os personagens de espírito $^{12}$ em oposição aos tolos. Os primeiros são aqueles comprometidos com a verdade e a transparência, que se recusam e mesmo não sabem agir de maneira eticamente ambígua (MAIA NETO, 2016, p. 282). Antes da crise cética, esses personagens adotam uma perspectiva que é chamada de ingênua, por não problematizar a verdade e as aparências (MAIA NETO, 2007A, p. 40). Sobretudo na primeira fase machadiana, aqueles personagens de espírito que não se harmonizam com a vida exterior se tornam problemáticos: loucos ou suicidas ${ }^{13}$. Esses personagens

\footnotetext{
${ }^{9}$ O paralelo pode revelar lacunas importantes nos pensamentos dos autores estudados. Exemplo disso se dá quando Margutti, ao estabelecer a comparação entre David Hume e Matias Aires tendo em vista o tema da vaidade, apresenta aquilo que pode ser considerada uma falha do pensamento humeano em relação à filosofia da religião. Conferir a esse respeito (MARGUTTI, 2003, p. 266-272).

${ }^{10}$ A leitura de Maia Neto encontra-se desenvolvida nas seguintes obras: (KRAUSE, 2005, p. 11-24); (MAIA NETO, 2007B); (MAIA NETO, 2007C, p. 212-226); (MAIA NETO, 2013, p. 59- 71); (MAIA NETO em ROCHA, 2016); (MAIA NETO, 2021, p. 102-116).

${ }^{11}$ Martins observa que a potência da forma literária machadiana faz resistência ao discurso filosófico estrangeiro, não sendo, por isso, mera exemplificação de uma dada filosofia. Trata-se, portanto, de um embate entre duas potências (2018, p. 57-58).

${ }^{12}$ Sob essa denominação cobrimos tanto os personagens masculinos como os femininos, de modo que há tanto homens como mulheres de espírito opostos aos personagens, também homens e mulheres, estratégicos.

${ }^{13}$ Exemplifica perfeitamente essa condição o protagonista do conto $O$ anjo Rafael: "Cansado da vida, descrente dos homens, desconfiado das mulheres e aborrecido dos credores, o Dr. Antero da Silva determinou um dia despedir-se deste mundo" (MACHADO DE ASSIS, 1956, p. 15). Os traços subjetivos de Antero explicitam sua inabilidade em lidar com a vida exterior, o que motiva sua decisão de retirada da existência:"O caso é que o nosso herói determinou matar-se, e para isso foi à casa da viúva Laport, comprou uma pistola e entrou em casa, que era à rua da Misericórdia" (MACHADO DE ASSIS, 1956, p. 15). Não deixa de ser irônico que um
} 
são divididos em basicamente dois grupos: há os problemáticos que após seus sofrimentos e desventuras encontram a paz doméstica - como é o caso do Antero de Anjo Rafael - e os que, após as desventuras, não erigem essa condição; nesse caso, os aguarda o suicídio ou a loucura (MAIA NETO, 2007A, p. 71-74). A paz doméstica se consuma quando os homens de espírito encontram as mulheres de espírito, personagens que, de maneira semelhante aos primeiros, rejeitam a vida exterior, preferindo a paz doméstica (MAIA NETO, 2007A, p. 51-55). As mulheres de espírito são mais numerosas na primeira fase machadiana, sendo um exemplo aquela que institui com Antero a paz doméstica, a Celestina em O anjo Rafael ${ }^{14}$ (MAIA NETO, 2016, p. 283).

Os personagens, ao realizarem o casamento, garantiam a paz doméstica, contudo, quando a vida exterior invade o casamento, ficam sem ambiente, perdendo acesso a uma verdade unívoca e transparente e tornando-se deslocados para lidar com a nova situação, polissêmica e opaca. Nesse momento o casamento torna-se mesmo o centro da vida exterior, o que se dá ao longo da segunda fase machadiana e se consolida com Dom Casmurro (MAIA NETO, 2007A, p. 46). Os personagens estratégicos, por sua vez, estarão perfeitamente à vontade sob a hegemonia da vida exterior. Como, então, caracterizar esses personagens?

Em primeiro lugar, convém assinalar que a conduta dessas personagens diverge tanto das personagens de espírito quanto do observador cético. (MAIA NETO, 2007A, p. 78-79). Os personagens estratégicos ${ }^{15}$ adotam uma perspectiva que se vale de um conhecimento intuitivo das regras da vida social, cuja determinação pelas aparências é muito forte (MAIA NETO, 2007A, p. 25). A conduta desses personagens é instrumental. Além disso, ela é calcada na distância que há entre a conduta exterior e os estados subjetivos (MAIA NETO, 2007A, p. 38-39). Se necessário para atingir os objetivos almejados, esses personagens utilizam a dissimulação e mentira (MAIA NETO, 2016, p. 282). Os estrategistas da primeira fase têm uma concepção de vida social como dramatúrgica, os papéis aéticos sendo desempenhados por canastrões (MAIA NETO, 2007A, p. 38-39). A definição desse tipo de personagem na primeira fase machadiana é mais negativa, $o$ que fica implícito pela possibilidade de conversão desses personagens em personagens de espírito (MAIA NETO, 2007A, p. 49-50).

Na segunda fase, conforme a própria caracterização da vida exterior se torna menos severa, o próprio personagem estratégico passa a ser descrito de forma mais rebuscada (MAIA NETO 2007A, p. 65-66). Conforme se constitui a segunda fase, a esfera das essências, relacionada com a verdade, deixa de se dar de maneira inequívoca. A partir daí toma seu lugar o campo das conveniências, fazendo da verdade algo impermeável (MAIA NETO, 2007A, p. 50). Os personagens estratégicos não são mais os "bonecos sem consciência" de uma vida social despersonalizada (MAIA NETO, 2007A, p. 49), tornando-se os medalhões, complexos ao ponto de exporem os pormenores de sua concepção estratégica da vida. Essa exposição se dá no conto

residente da rua da Misericórdia seja salvo de um projeto de suicídio por um acaso, ou uma intromissão do destino. É curioso observar que, se para o medalhão a ironia é algo que deve ser evitado, o destino - uma das faces da Natureza - ao longo dos textos de Machado é constantemente irônico. A ironia, portanto, aparece tanto no plano individual - nas ações de personagens como o medalhão e Janjão, por exemplo - como em um plano metanarrativo: enquanto destino, Pandora pode assim ser vista como a personagem mais presente em toda a obra machadiana.

14 "Quando o coronel saiu, Celestina pôs os braços à roda do pescoço do marido, e disse com um sorriso entre lágrimas: - Ao pé de ti e de minha mãe, que mais quero na terra?" (MACHADO DE ASSIS, 1956, p. 57).

${ }^{15}$ Assim como no caso dos personagens de espírito, adotando a perspectiva estratégica existem tanto personagens masculinos como femininos, os homens que a adotam sendo denominados na primeira fase de tolos (MAIA NETO, 2007A, p. 25). As mulheres estratégicas são menos numerosas na primeira fase machadiana, ganhando mais espaço na segunda (MAIA NETO, 2007A, p. 5155). Isso acontece de maneira concomitante à mudança de tratamento que esse tipo de personagem recebe de uma fase para outra: deixam de ser considerados simplesmente como personagens aéticos para serem caracterizados de maneira menos negativa e mais complexa (MAIA NETO, 2007A, p. 38-39), ou seja, na segunda fase deixam de ser tolos para serem mais bem representados como medalhões, em referência ao conto Teoria do medalhão (MAIA NETO, 2007A, p. 45). 
Teoria do medalhão, em que o pai expõe ao filho Janjão na forma de conselhos as táticas que deve utilizar para assumir o lugar de medalhão completo ${ }^{16}$ (MAIA NETO, 2007A, p. 45). A reflexão realizada pelo medalhão será instrumental ${ }^{17}$, pois qualquer reflexão que não seja dessa natureza compromete a perspectiva estratégica. Eis aí o sentido da advertência dada a Janjão pelo pai ${ }^{18}$ sobre os problemas das ideias fixas (MAIA NETO, 2007A, p. 79).

$\mathrm{Na}$ esteira dos elementos discutidos acima, nos servimos da metodologia do paralelo e do traço da expressão intuitiva da Matriz Colonial em conjunto com a perspectiva estratégica para fundamentarmos os conteúdos da próxima etapa da nossa pesquisa.

\section{"Guardadas as proporções..."}

O passo seguinte é estabelecer um paralelo entre a ação instrumental apresentada ao aprendiz de medalhão e os conceitos maquiavelianos de virtu e fortuna, tendo em vista a advertência final do conto ${ }^{19}$. Notamos que nossa proposta não constitui uma sobreposição em que os conceitos se identificam cabalmente, mas de uma situação mais complexa que compreende tanto pedras de toque como divergências importantes, cujos exemplos em ambos os casos procuraremos apontar adiante da melhor maneira possível.

Uma primeira diferença que devemos salientar trata da distinção entre os tipos de virtù. Segundo Bignotto, Maquiavel distingue entre a virtù exercida nas repúblicas e aquela, por exemplo, do príncipe novo, que é o seu paroxismo. Essas distinções não compreendem a virtù como uma espécie de resumo de toda forma de ação humana (2005, p. 152-153), como é, por sua vez, a maneira como o personagem do conto machadiano entende a ação do medalhão, ou seja, valendo de modo amplo para a vida social. Se uma mera sobreposição entre a virtù e a ação estratégica do medalhão, portanto, não é perfeitamente adequada, recusar paralelos e elementos de toque entre os conceitos equivaleria ao extremo oposto, de modo que identificar esses paralelos pode ter a vantagem de ajudar na compreensão mais cabal do agir humano, isso sem perder de vista as diferenças marcantes.

Assinalado um primeiro exemplo das diferenças que encontraremos entre os conceitos de ambos os autores e sugerida a importância do paralelo, passemos a algumas semelhanças. Comecemos pela convergência entre virtù e fortuna como importante para o entendimento de ambos os conceitos em Maquiavel.

Para o secretário florentino esses dois elementos são pólos que devem ser compreendidos conjuntamente, pois encarando a ação humana por apenas um dos prismas pode-se tomar, pelo lado da virtu, as forças humanas como imbatíveis e, caso se considere exclusivamente a fortuna, pode-se cair num determinismo inescapável (BIGNOTTO, 2003, p. 28). Algo semelhante pode ser encontrado na ação estratégica presente no conto machadiano. Com o medalhão tanto há a preocupação com o êxito social por meio do depuramento do aprendizado dos seus procedimentos ${ }^{20}$, como a consciência do peso do destino. Aliás, é essa caracterização

\footnotetext{
${ }^{16}$ A referência encontra-se em OC II p, 263. Adiantamos que, fundamentalmente, aquilo que separa o medalhão completo do incompleto é o uso da ironia, que o segundo aprende a abafar.

${ }^{17} \mathrm{O}$ critério de avaliação sobre as ações humanas no conto é o da conseqüência benéfica para o agente, ou seja, as personagens estratégicas (MARTINS, 2018, p. 67).

${ }^{18}$ Há um ponto importante nesse sentido observado por Martins, que é o fato do pai de Janjão ensinar uma arte que ele mesmo não dominou na prática, conhecendo apenas a teoria $(2018$, p. 68).

19 "Guardadas as proporções, a conversa desta noite vale o Príncipe de Maquiavel" (OC II, p. 267). Segundo o levantamento de Jean-Michel Massa, uma edição contendo tanto uma tradução em francês d'O príncipe, bem como fragmentos de outras obras do secretário florentino, acha-se ocupando o número 110 na biblioteca do Bruxo do Cosme Velho (2008, p. 44).

20 "- Digo-lhe que o que vosmecê me ensina não é nada fácil.
} 
do destino oferecida pelo medalhão que nos permite arriscar uma aproximação com a fortuna maquiaveliana ${ }^{21}$. Vejamos como o medalhão define a vida para seu filho, o aprendiz: "A vida, Janjão, é uma enorme loteria; os prêmios são poucos, os malogrados inúmeros, e com os suspiros de uma geração é que se amassam as esperanças de outra" (OC II, p. 262). Essa descrição dos 'suspiros de uma geração como o que amassa as esperanças de outra', recorda a marcha dos séculos que Pandora, ou a Natureza, revela no delírio a Brás Cubas ${ }^{22}$. O medalhão descreve a vida como uma loteria cheia de malogros. Pandora é a própria vida ${ }^{23}$, mãe e inimiga da humanidade ${ }^{24}$. A Pandora machadiana partilha com a fortuna a capacidade de retirar as conquistas humanas. Bignotto atribui à deusa da roda romana a capacidade de retirar tudo que os seres humanos conquistam quando decide, sem aviso, mudar os rumos dos acontecimentos ${ }^{25}(2003$, p. 26), de maneira análoga, porém com capricho particular, age a Pandora machadiana ${ }^{26}$. Desse modo, assim como a virtù demanda para sua adequada compreensão a ligação com o conceito de fortuna em Maquiavel (BIGNOTTO, 2003, p. 24), entender a ação estratégica do medalhão também passa pela consideração dos caprichos da Pandora machadiana.

Notemos que a primeira lição oferecida ao aprendiz de medalhão pelo pai é precisamente a natureza da vida: "Isto é a vida; não há planger, nem imprecar, mas aceitar as coisas integralmente, com seus ônus e percalços, glórias e desdouros, e ir adiante" (OC II, p. 262). Essa fala do medalhão vem logo após a constatação de que a vida é uma loteria. Tomemos esses dois elementos: primeiro, a vida é uma loteria; segundo, apesar dessa imprevisibilidade, é preciso não desanimar. Esses dois traços da relação do medalhão com Pandora assemelham-se a um vínculo que o próprio Maquiavel estabelece entre a fortuna e a virtu quanto à capacidade dos seres humanos de alterar o próprio destino. Assim se exprime o secretário florentino após afirmar que os seres humanos são capazes de seguir de perto os desígnios da fortuna, mas não fazer oposição direta ao seu destino: "Por isto não devem desesperar, já que ignoram o seu fim, e a sorte caminha de modo oblíquo e desconhecido. Devem sempre esperar, e nesta esperança não se devem entregar, mesmo nas mais adversas circunstâncias" (2000, p. 285). Não é preciso ir muito longe para encontrarmos a ligação que a esperança possui com Pandora. Curioso notar também que, de acordo com uma versão do mito, Pandora recebe de alguns deuses do Olimpo habilidades específicas; de Atena aprende a arte da tecedura (KERÉNYI, 2015, p. 197).

Como se dá, então, o conhecimento que o medalhão trava da vida - entendida aqui como Natureza ou Pandora - se ele se mostra avesso à reflexão? Nossa hipótese é a seguinte. Em

\footnotetext{
- Nem eu te digo outra coisa. É difícil, come tempo, muito tempo, leva anos, paciência, trabalho, e felizes os que chegam a entrar na terra prometida! Os que lá não penetram, engole-os a obscuridade. Mas os que triunfam!" (OC II, p. 266).

${ }^{21}$ Adiantamos que haverá igualmente importantes diferenças, que discutiremos mais adiante.

22 "Os séculos desfilavam num turbilhão, e, não obstante, porque os olhos do delírio são outros, eu via tudo o que se passava diante de mim - flagelos e delícias - desde essas coisas que se chamam glória até essa outra que se chama miséria, e via o amor multiplicando a miséria, e via a miséria agravando a debilidade" (OC I, p. 608). É interessante observar que o conto Teoria do medalhão é publicado originalmente na Gazeta de Notícias em 18 de dezembro de 1881, um ano depois da publicação das Memórias Póstumas, lançado originalmente na Revista Brasileira entre 15 de março e 15 de dezembro de 1880, sendo publicado posteriormente em volume no ano de 1881. Segundo Maia Neto, é possível aproximar o narrador de Memórias Póstumas com o medalhão, pois o próprio Brás Cubas é uma personagem que falha repetidamente ao tentar adotar a perspectiva estratégica, cujo obstáculo é a atitude reflexiva (2007 A, p. 96). Além disso, tanto Brás Cubas (OC I, p. 602-603) quanto o medalhão (OC II, p. 263) apontam os perigos das chamadas ideias fixas.

23 "Quem me pôs no coração esse amor da vida, senão tu? E, se eu amo a vida, por que te hás de golpear-te a ti mesma, matando-me?" (OCl, p. 608).

24 "- Chama-me Natureza ou Pandora; sou tua mãe e tua inimiga" (OC I, p. 607).

${ }^{25}$ É curioso também que o autor remeta ao mito de Pandora comentando sobre os riscos da ação política. Conferir a esse respeito (BIGNOTTO, 2003, p. 21).

26 “Porque levo na minha bolsa os bens e os males, e o maior de todos, a esperança, consolação dos homens. Tremes?

- Sim; o teu olhar fascina-me.

- Creio; eu não sou somente a vida; sou também a morte, e tu estás prestes a devolver-me o que te emprestei" (OC I, p. 607-608).
} 
primeiro lugar, o medalhão diferencia reflexão de instrução ${ }^{27}$. A primeira pressupõe originalidade e imaginação ${ }^{28}$, a segunda requer do intelecto apenas seu uso moderado, disciplinado e dirigido ao equilíbrio comum (OC II, p. 264). Em segundo lugar, esse conhecimento da Natureza é intuitivo, não sistemático. Compreendemos o sentido de 'intuitivo' aqui no horizonte do conceito marguttiano de Matriz Colonial, cuja influência, julgamos, se faz sentir na forma de apresentar os efeitos da vida presente na obra machadiana expressa na visão de mundo do personagem medalhão: com um pessimismo cético, de caráter intuitivo, não sistemático, avesso a elucubrações teóricas e acentuados pragmatismo e expressivismo - cordialidade. Para reforçar esse ponto, recorremos mais uma vez ao Capítulo VII das Memórias Póstumas, onde Brás Cubas afirma acompanhar o desfile dos séculos com olhos do delírio, que eram outros $(\mathrm{OCI}, \mathrm{p} .608)$. Mas esses olhos são outros em relação a quê? No capítulo seguinte, ele afirma que a Razão tornava a casa, pedindo a retirada da Sandice (OC I, p. 609-610). Ora, ainda que com os olhos do delírio, Brás Cubas não deixa de ter uma compreensão do que se passa, mesmo que nos limites da sua condição humana (OC I, p. 608-609). Essa compreensão dada pelo coração, intuitivamente, não é sistemática; é a mesma que o medalhão dispõe para compreender a vida. Finalmente, importa observar que essa intuição sobre a vida tem um aspecto eminentemente pragmático: os percalços que o medalhão deve evitar para atingir o sucesso. A ação estratégica do medalhão funciona como uma espécie de calção para as ambições, caso seja-se acometido pelos "desdouros" da vida (OC I, p. 262). De maneira parecida, o secretário florentino atribui à virtù a finalidade exclusiva de obter uma função de mando na sociedade (BIGNOTTO, 2003, p. 25).

Segundo Maia Neto, as personagens femininas exercem um papel importante na representação da temporalidade (2007A, p. 56; 135). Pandora representa exemplarmente essa dimensão no delírio de Brás Cubas, ao chamá-lo de mero "minuto" e desdenhá-lo, pois não lhe interessa o minuto que passa, mas o que vem; a vida, portanto, a Natureza, é tempo, e este é uma de suas facetas (OC I, p. 608-609). A semelhança com a deusa fiandeira Laquesis se faz evidente quando recordamos que essa divindade também era conhecida como a natureza (COMMELIN, 1997, p. 7). Mas como isso fortalece o paralelo com a fortuna de Maquiavel?Ao analisar as relações entre virtù e fortuna, o secretário florentino mostra que a ação humana pode intervir nos acontecimentos, mas não contrapor-se inteiramente aos desígnios da deusa da roda; ao considerar que os indivíduos estão aptos a seguir o desenrolar da fortuna, mas sem desafiar diretamente seu destino, Maquiavel afirma que isso"Ihes permite urdir uma trama sem romper um só fio" (2000, p. 285). Essa figura da urdidura é precisamente o que caracteriza a atividade das Parcas, entre as quais, Laquesis.

A virtù esbarra nos limites da fortuna, pois a humanidade tende a repetir as ações que funcionaram. Ao observar esse comportamento, Maquiavel considera que o mundo não enfrentou nenhuma mudança substancial (2000, p. 190). Desse modo, observar a história não tem como fito adquirir cultura ou erudição, mas sim um aprendizado próprio calcado na repetição das ações humanas (BIGNOTTO, 2003, p. 13-14). A virtù apresenta dois traços que ajudam a compreender suas limitações: a primeira diz respeito ao agente, a segunda, ao cenário. Em relação ao

\footnotetext{
27 "Ser medalhão foi o sonho da minha mocidade; faltaram-me, porém, as instruções de um pai, e acabo como vês, sem outra consolação e relevo moral, além das esperanças que deposito em ti" (OC II, p. 262). O diálogo entre pai e filho é uma transmissão de instruções.

28 "- Farei o que puder. Nenhuma imaginação?

- Nenhuma; antes faze correr o boato de que um tal dom é ínfimo.

- Nenhuma filosofia?

- Entendamo-nos: no papel e na língua alguma, na realidade nada. ' Filosofia da história', por exemplo, é uma locução que deves empregar com frequência, mas proíbo-te que chegues a outras conclusões que não sejam as já achadas por outros. Foge a tudo que possa cheirar a reflexão, originalidade, etc. etc." (OC II. p. 266).
} 
agente, o limite da virtù aparece pela tendência em repetir ações que já foram feitas. No que diz respeito ao cenário, temos a instabilidade do mundo, que torna inviável uma única forma de agir como meio de se obter sucesso (BIGNOTTO, 2003, p. 26). A tendência a observar a história, não para obter erudição, mas para desenvolver um aprendizado específico baseado na repetição, aparece quando o medalhão recomenda ao filho que decore a terminologia científica sem profundidade, pois deve tomar as armas do seu próprio tempo (OC II, p. 264). Além disso, denota ainda que há uma espécie de ciência própria ao medalhão ${ }^{29}$, que está relacionada com "uma certa atitude de deus Término", ou seja, com fronteiras ${ }^{30}$ e demarcações. Essa tendência de repetir as ações consagradas é o que o medalhão prescreve a Janjão em várias ocasiões, por exemplo, no emprego da filosofia - que não deve transcender"nunca os limites de uma invejável vulgaridade (OC II, p. 266) - e no uso do vocabulário ${ }^{31}$. Já a instabilidade do mundo aparece nas chamadas "oitivas com o tempo", única maneira de determinar, por exemplo, os destinos das ciências, podendo estar "usadas e divulgadas" ou permanecerem "novas" (OC II, p. 264).

Finalmente, temos o aspecto da virtù relacionado com o véu erguido entre essência e aparência. O secretário florentino reconhece esse hiato, de modo que inexiste uma única perspectiva que equivalha à essência de um acontecimento, desse modo, as ações humanas se tornam opacas no seu significado íntimo e a subjetividade pode ter múltiplos significados por trás de cada gesto aparente (BIGNOTTO, 2003, p. 35-36). É necessário, portanto, saber guardar as aparências mesmo das qualidades que não se possuam. O Capítulo XVIII De que formas os príncipes devem guardar a fé é paradigmático. Apresentando as qualidades da raposa e do leão como complementares e a necessidade de quebrar a palavra e não respeitar as conveniências, o secretário florentino alerta que é "necessário disfarçar muito bem esta qualidade e ser bom simulador e dissimulador" (1974, p. 74). Não é imprescindível, portanto, possuir as qualidades da fidelidade e da probidade, basta aparentá-las: "Antes, teria eu a audácia de afirmar que, possuindo-as e usando-as todas, essas qualidades seriam prejudiciais, ao passo que aparentando possuí-las, são benéficas; por exemplo: de um lado, parecer ser efetivamente piedoso, fiel, humano, íntegro, religioso, e de outro, ter o ânimo de, sendo obrigado pelas circunstâncias a não o ser, tornar-se o contrário" (MAQUIAVEL, 1974, p. 74). O príncipe deve aparentar essas qualidades aproveitando-se da debilidade de julgamento da maioria das pessoas (MAQUIAVEL, 1974, p. 75), ou seja, da inaptidão para desvelar os estados subjetivos sob o verniz das aparências. Isso não significa, entretanto, que a manutenção das aparências redunde necessariamente em uma essência corrompida por baixo delas, mas apenas que o campo do político é um lugar onde não se pode promulgar a verdade dos valores, pelo menos aqueles que os indivíduos tipicamente recebiam da tradição cristã (BIGNOTTO, 2007, p. 161).

Em relação ao medalhão, esse tema da incongruência entre essência e aparência se mostra em dois aspectos principais. O primeiro é a importância da aparência pelos benefícios

\footnotetext{
29 "[...] e esse fenômeno, tratando-se de um medalhão, é que não seria científico" (OC II, p. 265).

30 Utilizamos o termo "fronteira", pois essa terminologia permite estabelecer mais um ponto de contato da ação do medalhão com o conceito de virtu maquiaveliana. Bignotto apresenta o conceito de fronteiras da ética em Maquiavel. Esse conceito se mostra quando certos regimes políticos, como a tirania, ainda que atingindo as raias da violência, permanecem, não obstante, produtos da ação humana, estabelecendo os limites da ética (BIGNOTTO, 2007, 156-157). "O tirano não extingue a sociabilidade natural dos homens, não constrói o lugar do não político, ele mostra, ao contrário, que na forma mais degradada do governo continua a existir um grão daquilo que chamamos político" (BIGNOTTO, 2007, p. 172). Essa delimitação do político também explicita os limites da ética, ou seja, sua incapacidade de evitar a violência (BIGNOTTO, 2007, p. 173). Interessa para nossa pesquisa que as fronteiras da ética, conforme nos apresenta Bignotto, não significam um campo de oposição entre ética e política.

31 "Alguns costumam renovar o sabor de uma citação intercalando-a numa frase nova, original e bela, mas não te aconselho esse artifício; seria desnaturar-lhe as graças vetustas. Melhor do que tudo isso, porém, que afinal não passa de mero adorno, são as frases feitas, as locuções convencionais, as fórmulas consagradas pelos anos, incrustadas na memória individual e pública" (OC II, p. 264).
} 
da publicidade. A publicidade é dividida pelo medalhão em dois tipos. A primeira, "constante, barata, fácil, de todos os dias" (OC II, p. 265) requer para sua conquista o oposto do que Maquiavel prescreve para a obtenção dos favores da fortuna: se o secretário florentino fala de ações impetuosas, audaciosas e opostas à circunspecção (1979, p. 105), o medalhão fala que para se obter a publicidade, devem-se empregar ações de pouca monta, mas de regularidade inquebrantável. A somatória constante de pequenas atitudes que fazem aparecer o nome do candidato a medalhão: eis como se conquista a publicidade, pois as ações grandiloquentes parecerão estouvadas (OC II, p. 265): "Os sucessos de certa ordem, embora de pouca monta, podem ser trazidos a lume, contando que ponham em relevo a tua pessoa" (OC II, p. 265). A segunda forma de se conquistar a publicidade ensinada pelo medalhão é angariando a estima pública por meio de reproduções artísticas: bustos e retratos (OC II, p. 265-266). Se o primeiro tipo de publicidade não encontra paralelo no 'livrinho' do secretário florentino, com o segundo é possível estabelecer uma relação. Maquiavel fornece como exemplo Fernando de Aragão que, pela fama e pela glória, passou de um rei fraco à condição de primazia entre as majestades cristãs. Quando alguém realiza algo extraordinário, de bem ou de mal, o príncipe deve, ao premiar ou punir, fazer de maneira tal que isso lhe dê margem para receber amplos comentários (1979, p. 93-92). Além disso, o secretário florentino lembra a importância das artes para a construção da estima pública do príncipe: "E como todas as cidades estão divididas em artes ou corporações de ofício, deve ocupar-se muito destas, indo ao seu encontro algumas vezes, dar provas de afabilidade e munificência, mantendo sempre integral, contudo, a majestade da sua dignidade, a qual não deve faltar em nada (MAQUIAVEL, 1979, p. 96).

O segundo aspecto da dissonância entre essência e aparência localizado nas instruções do medalhão é a necessidade da dissimulação da ironia. Margutti pontua que o ironismo machadiano tem como pressuposto a constatação de uma ausência de novidade sob o sol, no espírito do Eclesiastes (2007, p. 205-206). Essa ausência de novidade aparece como o traço da visão sobre a natureza humana segundo a qual ela apresenta traços recorrentes ao longo da história. Ora, essa visão pode ser encontrada também em Maquiavel (BIGNOTTO, 2003, p. 19). Destacamos também que a ironia machadiana ilustra o manejo da aparência que o medalhão deve dominar, ao não explicitar através da ironia ${ }^{32}$, seu próprio estado subjetivo:

Um grave pode ter seus momentos de expansão alegre. Somente - e este ponto é melindroso...

- Diga.

- Somente não deves empregar a ironia, esse movimento de canto de boca, cheio de mistérios, inventado por algum grego da decadência, contraído por Luciano, transmitido a Swift e Voltaire, feição própria dos céticos e desabusados. Não. Usa antes a chalaça, a nossa boa chalaça amiga, gorducha, redonda, franca, sem blocos, nem véus, que se mete $\mathrm{p}^{33}$ ela cara dos outros, estala como uma palmada, faz pular o sangue nas veias, e arrebentar de riso os suspensórios. Usa a chalaça (OC II, p. 267; grifo nosso).

A chalaça substitui convenientemente a ironia, pois, por ser sem blocos, é simples e direta e não carece de véus. Além disso, a ironia deve ser evitada por ser expressão da melancolia e esta impele em direção a algo que o medalhão deseja sufocar: a reflexão. Para tanto, o meda-

\footnotetext{
32 Maia Neto também atribuiu à ironia algo que o medalhão deseja evitar (2007B, p. 215).

33 "Machado refere-se provavelmente a Sócrates, fonte fundamental do ceticismo grego, em particular da Nova Academia. Além de Sócrates, Timão, figura crucial na divulgação e talvez mesmo na construção do ceticismo de Pirro de Elis, foi um grande satirista dos filósofos dogmáticos" (MAIA NETO, 2007B, p. 215).
} 
Ihão prescreve uma conduta calcada no divertimento ${ }^{34}$ pascaliano ${ }^{35}$ : "Com este regime, durante oito, dez, dezoito meses - suponhamos dois anos - reduzes o intelecto, por mais pródigo que seja, à sobriedade, à disciplina, ao equilíbrio comum" (OC II, p. 264).

O estado melancólico deve ser evitado, pois será um obstáculo para o medalhão. A melancolia enseja à reflexão ${ }^{36}$, fértil para as idéias. Um elemento que contribui para a aversão do medalhão às ideias próprias é o seu caráter espontâneo e súbito (OC II, p. 263), o que torna o comportamento imprevisível - um ponto de extrema vulnerabilidade para a conduta estratégica. Nesse aspecto, assinalamos uma divergência entre os modos de considerar a ação teleológica maquiaveliana e machadiana. Se para o secretário florentino o julgamento das ações humanas é uma habilidade rara ${ }^{37}$, o Bruxo do Cosme Velho pondera que, pelo menos no que diz respeito à detecção da posse dessas ideias - ou, por outra, da melancolia - o faro do vulgo é apurado, sendo a presença desse elemento o que permite distinguir o medalhão completo do incompleto (OC II, p. 263).

\section{Considerações finais}

Ao situarmos paralelamente o Bruxo do Cosme Velho e o secretário florentino pudemos comparar a riqueza de interpretações que uma obra como a machadiana provoca. Alicerçaram nossa pesquisa especialmente os trabalhos de Margutti e Maia Neto. A Matriz Colonial marguttiana fornece os elementos do intuitivismo, pragmatismo e cordialidade. Além disso, a ironia enquanto um terço de zombaria e dois terços de pessimismo - marca o pessimismo cético. Já a forma da criação literária como indissolúvel da filosofia encontrada na ficção machadiana conforme a interpretação de Maia Neto se mostra adequada para lidar com a polissemia inerente à experiência humana. Isso possibilita múltiplas leituras da obra machadiana - das quais expusemos quatro para em seguida embasar a nossa -, todas, no entanto, coerentes em reconhecer a presença de alguma forma de pessimismo, ceticismo e ironismo. Finalmente, destacamos que a polissemina da vida social é um aspecto que se encontra na perspectiva estratégica, que reconhece o peso das aparências.

Ao traçar o paralelo entre os dois autores, ganham relevo os aspectos específicos presentes em cada um. Como exemplo, tratamos a diferença entre a Pandora machadiana e a for-

\footnotetext{
34 "Assim, são-lhes dados encargos e afazeres que os fazem quebrar a cabeça desde o raiar do dia. Aí está, direis, uma estranha maneira de torná-los felizes; que se poderia fazer melhor para torná-los infelizes? Como, o que se poderia fazer? Bastaria retirar-Ihes todas essas preocupações, porque então eles se veriam, pensariam naquilo que são, de onde vêm, para onde vão, e assim nunca é demais ocupá-los e desviá-los disso. E eis que, depois de preparar-lhes tantos afazeres, se ainda tiverem algum tempo livre, aconselha-se que o empreguem em se divertir, e jogar, e ocupar-se sempre por inteiro" (Pensamentos, Lafuma, 139, p. 56-57). Essa menção aos jogos nesse fragmento pascaliano coincide com uma das prédicas do medalhão para abafar o surgimento das idéias próprias: "O voltarete, o dominó e o whist são remédios aprovados. O whist tem até a rara vantagem de acostumar ao silêncio, que é a forma mais acentuada da circunspecção" (OC II, p. 263). A circunspecção simula a gravidade pela aparência e pelo efeito, sem corresponder em essência à melancolia.

${ }^{35}$ Margutti e Maia Neto atestam a influência de Pascal em Machado de Assis. Para Margutti, a influência pascaliana se dá em conjunto com a de outros autores como Sanches, Montaigne e Erasmo, na convergência para o pessimismo cético originado na Matriz Colonial Barroca (2007, p. 207). Para Maia Neto, a forma de ceticismo contida na ficção machadiana tem relações com o pirronismo, porém, conforme este é assimilado às formas modernas, incluindo aí, sobretudo, Pascal (2016, p. 277).

${ }^{36}$ Margutti observa que o pessimismo cético machadiano apresenta caráter melancólico, que opera um desvelamento do caráter vão da finitude e da vaidade no espírito denunciativo do Eclesiastes (2007, p. 201).

37 "É que os homens, em geral, julgam mais pelos olhos do que pelas mãos, pois todos podem ver, mas poucos são os que sabem sentir" (MAQUIAVEL, 1979, p. 75). Esse trecho d'O príncipe que enfoca a distância entre aparência e essência é revelador da ligação que existe entre ética e política em Maquiavel: "Falar, pois, das representações não implica dizer que a ética não tem ligação com a política. Corresponde a mostrar que a ética, vivida como costume, é a janela através da qual percebemos as ações humanas ('os homens julgam mais pelos olhos do que pelas mãos, pois é dado a todos ver e a poucos perceber'), sem que isso explicite a verdade ou não das proposições que nos guiam e revele a essência dos atos julgados" (BIGNOTTO, 2007, p. 161).
} 
tuna maquiaveliana, tendo em vista que natureza e fortuna para o secretário florentino não são uma só divindade, como ocorre em Machado, em cuja obra as facetas de Pandora são variadas, incluindo a natureza, o tempo, a sorte e a vida.

A fortuna em Maquiavel é compreendida como uma força disruptiva em relação aos cálculos humanos, a inconstância dos acontecimentos, o que torna claro que o ser humano não consegue sujeitar completamente o devir. A fortuna maquiaveliana não é encarada como uma instância todo-poderosa que rege o devir histórico (MÉNISSIER, 2012, p. 24-25). “O reconhecimento do papel eternamente perturbador da fortuna não conduz, portanto, ao fatalismo, mas consiste, ao contrário, num convite a não desanimar" (MÉNISSIER, 2012, p. 25). Se a exortação contra o desânimo ecoa também na obra do Bruxo do Cosme Velho, a grande diferença entre a Pandora machadiana e a fortuna maquiaveliana é que esta não é encarada como inimiga das ações humanas, mas como mãe das ocasiões (MÉNISSIER, 2012, p. 25). Além disso, para Maquiavel há uma distinção entre fortuna e natureza (MÉNISSIER, 2012, p. 26). A natureza é uma potência de animação, que individualiza os seres humanos, cidades e povos durante algum tempo, o que abre espaço para a imperfeição e a tendência à corrupção. A natureza também é dinâmica e tende à expansão, como uma força de atuação. Nos seres humanos a natureza mostra seus efeitos enquanto desejo e frustração permanente (MÉNISSIER, 2012, p. 39-40).

A lógica natural que sustenta o devir cósmico parece obedecer, mais precisamente, a uma teleologia cega: está orientada numa direção e manifesta até uma intenção que concerne à espécie humana, mas essa direção permanece incompreensível e a intenção não é favorável ao desenvolvimento harmonioso das atividades dos homens (MÉNISSIER, 2012, p. 41).

No elenco das diferenças que o paralelo proporciona, temos também o conceito de virtù em relação à ação estratégica do medalhão. A virtù maquiaveliana carrega muitos significados, entre eles, o de uma moral propícia à política e a faculdade de se confrontar com a fortuna ou de se associar a ela para obter êxito, como uma espécie de par humano da deusa (MÉNISSIER, 2012, p. 60). À semelhança da ação estratégica do medalhão, a virtù é conhecimento e esforço; conhecimento - não raro intuitivo - da opção correta para a ocasião que se apresenta; esforço, enquanto energia de conquista que mobiliza a invenção de soluções (MÉNISSIER, 2012, p. 6061). Se o elemento da perseverança é pedra de toque entre a ação do medalhão e do indivíduo de virtù, elas se distanciam quando o secretário florentino qualifica a segunda como uma capacidade de transcender os limites habituais da humanidade, isso porque ela é ensinada pelo famoso mestre dos grandes heróis gregos: o centauro, metade homem e animal, que encarna a importância da ferocidade (MÉNISSIER, 2012, p. 61). Os mestres, portanto, separam as duas: Quíron e o pai de Janjão são modelos diversos para o ensino de duas formas diferentes de ação. Entretanto, para ambos, apesar das diferenças, é possível localizar a importância que a percepção dos estados subjetivos desempenha na vida social, tendo em vista a distância, a imprecisão, a confusão, a polissemia e mesmo a opacidade entre as aparências e as essências que as motivam e se dão enquanto fenômenos na arquitetônica das relações humanas.

A partir do que foi discutido, consideramos que o método do paralelo não constitui um simples decalque de um pensador por outro, mas sim de um cotejamento que cria o realce; assim como uma sombra projetada no seu jogo com as áreas de incidência direta de luz em uma tela barroca cria, pela interação, um destaque mútuo para ambas as áreas cujo conúbio é a tensão, o paralelo entre os conceitos filosóficos atende a um esclarecimento recíproco e permite uma compreensão mais aprofundada dos pensamentos ladeados. Tomando emprestado o sentido da sentença final do medalhão, concluímos assim: a partir de Machado, tomamos lições para a compreensão de Maquiavel, de Maquiavel, tomamos ferramentas para compreendermos Machado - e assim compreendemos um pouco melhor a experiência humana. 


\section{Referências}

BERNARDO, G. Quem me dera: o ceticismo de Machado de Assis. Revista Sképsis. São Paulo, v. 1, n. 1, p.171-183, 2007.

BIGNOTTO, N. As fronteiras da ética: Maquiavel. Em: NOVAES, A. (Org.). Ética. São Paulo: Companhia das Letras, 2007.

BIGNOTTO, N. Maquiavel republicano. São Paulo: Edições Loyola, 2005.

BIGNOTTO, N. Maquiavel. Rio de Janeiro: Jorge Zahar Editor, 2003.

COMMELIN, P. Mitologia grega e romana. Tradução de Eduardo Brandão. $2^{\text {a }}$ ed. São Paulo: Martins Fontes, 1997.

DIAS, Rosa Maria. "Autor de si mesmo": Machado de Assis leitor de Schopenhauer. Revista Kritérion. Belo Horizonte, n. 112, p. 382-392, 2005.

KERÉNYI, K. A mitologia dos gregos: vol. I: a história dos deuses e dos homens. Tradução de Octávio Mendes Cajado. Petrópolis: Vozes, 2015.

MACHADO DE ASSIS, J. M. Contos esparsos. Rio de Janeiro: Editora Civilização Brasileira, 1956.

MACHADO DE ASSIS, J. M. Obra completa em quatro volumes. São Paulo: Editora Nova Aguilar, 2015.

MAIA NETO, J. R. A evolução cética da filosofia na ficção de Machado de Assis ao longo de quatro encontros na Rua do Ouvidor. Argumentos. Fortaleza, n. 25, p. 102-116, 2021.

MAIA NETO, J. R. Machado de Assis: ceticismo e literatura. Em: KRAUSE, G. B. Literatura e ceticismo. São Paulo: Annablume, 2005.

MAIA NETO, J. R. Machado, um cético brasileiro: resposta a Paulo Margutti e a Gustavo Bernardo. Revista Sképsis. São Paulo, v. 1, n. 1, p. 212-226, 2007B.

MAIA NETO, J. R. O ceticismo na obra de Machado de Assis. São Paulo: Annablume, 2007A.

MAIA NETO, J. R. O delito capitolino. Aletria. Belo Horizonte, n. 1 v. 23, p. 59-71, 2013.

MAIA NETO, J. R. O desenvolvimento de uma visão de vida cética na ficção de Machado de Assis. Em: ROCHA, J. C. C. Machado de Assis: lido e relido. São Paulo: Alameda, Campinas: Editora UNICAMP, 2016.

MAQUIAVEL, N. Comentários sobre a primeira década de Tito Lívio. Tradução de Sérgio Bath. Brasília: Editora Universidade de Brasília, 2000.

MAQUIAVEL, N. O príncipe. Escritos políticos. Tradução de Lívio Xavier. São Paulo: Abril Cultural, 1979.

MARGUTTI, P. As idéias filosóficas de Francisco Sanches. Revista Sképsis. São Paulo, n. 5, p. 103$148,2010$.

MARGUTTI, P. História da filosofia do Brasil: O período colonial (1500-1822). São Paulo: Edições Loyola, 2013.

MARGUTTI, P. Machado, o brasileiro pirrônico? Um debate com Maia Neto. Revista Sképsis. São Paulo, n. 2, p. 183-209, 2007A. 
MARGUTTI, P. Reflexões sobre a vaidade dos homens: Hume e Matias Aires. Revista Kritérion, Belo Horizonte, n. 108, p. 253-278, 2003.

MARTINS, A. L. Machado de Assis: o filósofo brasileiro. Porto Alegre: Editora Fi, 2017.

MARTINS, A. L. O anjo e a besta: Pascal, Machado de Assis e a descristinianização do ceticismo. Belo Horizonte. 322f. Tese (Doutorado em Filosofia). Programa de Pós-Graduação em Filosofia do Departamento de Filosofia da Faculdade de Filosofia e Ciências Humanas, Universidade Federal de Minas Gerais (UFMG), 2018.

MARTINS, A. L. Sócrates sofista, Brás Cubas filósofo? Aletria, n. especial, p. 13-24, 2009.

MASSA, J. A biblioteca de Machado de Assis. Em: JOBIM, J. L. (Org.). A biblioteca de Machado de Assis. Rio de Janeiro: Toopbooks Editora, 2008.

MÉNISSIER, T. Vocabulário de Maquiavel. São Paulo: Martins Fontes, 2012.

NUNES, B. Machado de Assis e a Filosofia. Revista Travessia. Universidade Federal de Santa Catarina, n. 19, p. 7-23, 1989.

PASCAL, B. Pensamentos. Edição, apresentação e notas de Louis Lafuma. Tradução de Mário Laranjeira. São Paulo: Martins Fontes, 2005.

PAULA, M. F. Espinosa na obra de Machado de Assis. Santa Bárbara Portuguese Studies, v. 2, p. 1-18, 2018.

\section{Sobre o autor}

\section{Daniel Benevides Soares}

Doutor em Filosofia pela Universidade Federal do Ceará (UFC). Professor da Faculdade Católica de Fortaleza (FCF).

Recebido em: 27.08.2021.

Aprovado em: 30.09.2021.
Received: 27.08.2021.

Approved: 30.06.2021. 